\title{
Making sense of unfamiliar risks in the countryside: the case of Lyme disease
}

Afrodita Marcu ${ }^{\mathrm{a}}$, David Uzzell ${ }^{\mathrm{b}}$, and Julie Barnett ${ }^{\mathrm{a}}$

${ }^{a}$ Department of Information Systems and Computing, Brunel University, Kingston Lane, Uxbridge, Middlesex, UB8 3PH, UK

${ }^{\mathrm{b}}$ Department of Psychology, University of Surrey, Guildford, Surrey, GU2 7XH, UK

Acknowledgements: This research was supported by the Economic and Social Research Council (award number RES-229-25-0007) and was part of a 3-year interdisciplinary project on assessing and communicating animal disease risks to countryside users (project partners: Forest Research and the Department of Zoology, University of Oxford). We are grateful to Chris Quine, Principal Investigator, and also to Simon Richards (Richmond Park), Nigel Hester (National Trust, The Holnicote Estate, Exmoor), Mike Seddon and Richard Burke (The Forestry Commission, New Forest) for kindly supporting our data collection at the three sites. 


\section{Abstract}

The focus of this paper is on how popular representations of the countryside provide countryside users with a discursive framework to make sense of unfamiliar countrysidebased risks, taking Lyme disease as an example. Sixty-six semi-structured interviews were conducted with 82 visitors in Richmond Park, New Forest, and Exmoor National Park in the UK. The data was analysed using thematic analysis and was informed by social representations theory. The analysis indicated that a lay understanding of the risk of Lyme disease was filtered by place-attachment and the social representations of the countryside. Lyme disease was not understood primarily as a risk to health, but was instead constructed as a risk to the social and restorative practices in the context of the countryside. The findings suggest that advice about zoonoses such as Lyme disease is unlikely to cause panic, and that it should focus on the least intrusive preventative measures.

Keywords: countryside, identity, Lyme disease, place attachment, risk, social representations 
Making sense of Lyme disease

\section{Making sense of unfamiliar risks in the countryside: the case of Lyme disease}

\section{Introduction}

People are generally encouraged to use urban and rural green spaces for physical and psychological health benefits, and the countryside (a generic term by which we mean rural environments, forests, parks, etc.) is predominantly represented as a healthenhancing, restorative and therapeutic setting (e.g. Conradson, 2005; Karjalainen, Sarjala, and Raitio, 2010) with beneficial effects (Hartig, 2008). Yet the countryside is not a riskfree environment and it can harbour a variety of hazards ranging from the obvious (e.g. slippery paths), the well-known (e.g. forest fires), the common (e.g. sunburn), the manmade and natural (e.g. forest operations, changes in weather), to the rare and less familiar hazards such as zoonoses (e.g. Weil's disease, Lyme disease, etc). Given that the public are widely encouraged to use the countryside, the unfamiliarity of rare hazards poses a dilemma of how to provide adequate precautionary information without causing unnecessary alarm. The focus of this paper is on how popular representations of the countryside provide countryside users with a discursive framework to make sense of unfamiliar countryside-based hazards, taking Lyme disease (henceforth, LD) as an example.

One way to solve the 'health conundrum' between encouraging people to use the countryside and raising awareness about unfamiliar hazards without provoking alarm is 
to focus on risk communication strategies (Quine, Barnett, et al., in press). Thus, it becomes important to understand how the public respond to risk messages, how messages could be better delivered, and how the public can be motivated to engage in precautionary behaviour. It may be particularly instructive to consider how people make sense of unfamiliar risks when they know little about them, such as transmission routes, prevention, and long-term effects. When risk information is provided, what claims are made about likely behaviours and how are these claims warranted? What knowledge is sought, if any, in order to make sense of the risk? What values, norms and beliefs are invoked in the meaning-making process? One might expect that a situation of unfamiliarity gives greatest access to rules of thumb before discourses become well rehearsed and the boundaries of the 'hazard template' become clear. These questions were addressed as part of a multi-disciplinary project on Lyme disease which sought to examine and understand how people make sense of unfamiliar risks in the countryside. This research was part of the larger ESRC/NERC/BBSRC Rural Economy and Land Use programme investigating the social, economic, environmental and technological challenges faced by rural areas. This project brought together the disciplines of ecology, zoology, recreation, and social psychology to explore how best to communicate risk to countryside users, using LD as the exemplar.

We locate our exploration of these issues in the theory of social representations (Moscovici, 1984; 2000) which provides a useful insight into how individuals make sense of the unfamiliar (e.g., risks) and how they embed these risks into their everyday knowledge and practices. Social representations are ideas, images, and thoughts that 
constitute common sense and make up everyday thinking (Augoustinos and Walker, 1995), while also offering frameworks for explaining and evaluating events (Breakwell, 2001a). Social representations are formed via anchoring (the understanding of unfamiliar objects by comparing them to existing knowledge) and objectification (the transformation of unfamiliar and abstract notions into concrete common-sense realities) (Augoustinos and Walker, 1995). Social representations have been theorized to contain core elements, i.e. basic knowledge related to a set of values and beliefs, and peripheral elements, i.e. less stable components which change according to context (Abric, 1994). As noted by other researchers (e.g. Breakwell, 2001a; Devine-Wright, 2009), social representations can inform how novel risks are interpreted via anchoring and objectification, how they are evaluated, and how they are contested by individuals in relation to social practices or institutions. While we are interested in how LD is anchored and objectified, we are also interested in the functions that the representations of LD might serve. It has been suggested (Breakwell, 2001b; Joffe, 1999; 2003) that social representations are generally forged in ways that protect identity (where identity can incorporate both stable cognitions and everyday practices), therefore social representations of risks may be constructed in ways that minimize the impact on individuals' commonsense knowledge and social practices. This identity-protective function of social representations, referred to by Joffe (2003) as symbolic coping, is argued to stem from the emotive and social elements that underpin the process of representation, and also from individuals' motivations to maintain consistent values and beliefs. However, individuals may hold not only one representation of an object, but multiple and sometimes contradictory ones; this multiplicity of representational fields being termed cognitive polyphasia within the SRT 
framework (Jovchelovitch, 2002; 2008). Thus, it becomes important to understand which social representation is dominant in relation to an object of knowledge, and what factors, be they social or emotive, influence the dominance of one representation over another.

To provide a theoretical framework for reporting our empirical study, first we will describe the current state of LD in the UK. Second, we will characterise the main expected parameters of the public response to LD, third we will discuss the evidence of the relationship between place and the perception of health risks.

\section{Characterising Lyme disease}

Lyme borreliosis, or Lyme disease as it is popularly known, is transmitted by ticks infected with a bacterium (Borelia burgdorferi), although only a small proportion of ticks carry the bacteria. Ticks are small spider-like blood-sucking arachnids that parasitize their vertebrate hosts, including humans who can pick them up by coming into contact with vegetation or with animals on which ticks are not yet fully attached, e.g. dogs. About 800 people in the United Kingdom contract LD annually ${ }^{1}$, the peak times being March to October. The manifestations of LD include a specific 'bull's eye' skin rash, erythema migrans, and flu-like symptoms such as headaches, tiredness, muscle pains, joint aches and fever. LD can be diagnosed through clinical symptoms (i.e., skin rash) or by laboratory blood tests. It can be treated successfully with antibiotics in the first weeks after infection, although if left untreated it can lead to more debilitating symptoms, such as permanent damage to the central nervous system. LD is not contagious, and cannot be

\footnotetext{
1 Further information on Lyme disease can be found on the website of the Health Protection Agency, http://www.hpa.org.uk/Topics/InfectiousDiseases/InfectionsAZ/LymeDisease/
} 
contracted unless one has been into contact with ticks. Preventative measures against tick bites and LD include covering up skin, avoiding contact with vegetation, using insect repellent, and checking for tick bites after being in the countryside. Precautionary information about LD in the UK is usually provided by health-related organizations, e.g. the National Health Service (NHS), by countryside users' organizations (e.g. the Ramblers), by charities (e.g. Lyme Disease Action), and by leaflets provided by countryside recreation organizations (e.g. Forestry Commission, Center Parcs, the National Trust).

\section{Public responses to the risk of $L D$}

The few studies which have explored public attitudes to LD have largely focused on awareness of LD indicating that both public knowledge of LD and uptake of precautionary measures are generally low, both in the UK (Sheaves and Brown, 1995; Mawby and Lovett, 1998) and in other countries such as the US (Hallman, Weinstein, et al., 1995; Shadick, Daltroy, et al., 1997; Herrington, 2004). This is perhaps not surprising given the low severity of LD following prompt antibiotic treatment and the relatively low incidence (973 cases in England and Wales in 2009 as reported by the Health Protection Agency) in the context of the billions of visits made annually to the countryside ${ }^{2}$, although recent data indicate a steady increase in the reported incidence of LD in the UK, with $27 \%$ more cases in 2009 than $2008^{3}$. Notwithstanding this, there is public controversy around the incidence of LD, its diagnosis, treatment and the long-term effects

\footnotetext{
${ }^{2}$ According to a report by Natural England, 2.86 billion visits were made by the adult population in England from March 2009 to February 2010, see http://naturalengland.etraderstores.com/NaturalEnglandShop/NECR049

${ }^{3}$ Zoonoses Report UK 2009, provided by the Department for Environment, Food, and Rural Affairs, see http://www.defra.gov.uk/foodfarm/farmanimal/diseases/atoz/zoonoses/documents/reports/zoonoses2009.pdf
} 
(Aronowitz, 1991; Tonks, 2007; Ronn, 2009). This controversy is mainly reflected in the activities of patients' action groups and in media representations of LD as an underreported and essentially chronic illness (e.g. MacAskill, 2009).

However, the focus on awareness alone does not provide us with any insight as to how people who use the countryside actually make sense of LD and its risk. Given that the risk of LD describes both an actual phenomenon and a social construction, our research focuses on the patterns of lay understanding of this risk and the factors that shape the understanding of the necessary precautionary measures. The particular interest of this paper, given that LD is a place-based risk, is on identifying the way in which understandings of LD are located within, and anchored to, wider social representations and practices associated with the countryside.

Paradoxically, the characteristics of LD may facilitate public responses of both panic and distancing: its transmission via tick bites and the public controversy around the long-term effects of LD would suggest that people may respond with revulsion, panic and outrage, while its low incidence and restricted routes of transmission might engender responses of denial, distancing, or apathy. The SRT framework would predict that the social representations of LD might be polemical (Moscovici, 1988; Breakwell, 2001a), i.e. the risk of LD would be disputed and anchored in public discourses of controversy and uncertainty. However, it could also be argued that the public understanding of the risk of LD is dependent upon the existing objects of knowledge to which LD is anchored, and upon the emotive and social factors that enable such anchoring. Given that information is 
filtered by values (Stern and Dietz, 1994; Opotow and Weiss, 2000), and that lay risk reasoning is a reflection of how people frame risk in relation to everyday practices and value-commitments (Horlick-Jones, Walls, and Kitzinger, 2007), we would suggest that the risk of LD is likely to be filtered by the values and social practices that people attach to the countryside and even to identities as countryside users.

\section{The context of the countryside}

The context of the countryside (by which we mean forests, urban parks, moorland, heathland, coastal paths) is important not only as the place where the risk of LD occurs, but also as a place where people live, work and seek recreation and restoration. The countryside is often represented as a 'rural idyll' (Halfacree, 1995), as a place with therapeutic properties (Conradson, 2005), and as conducive to psychological well-being (Smith and Baum, 2003). Moreover, the countryside is prone to encourage place attachment, i.e. an emotional bond between individuals and the places and spaces they visit or inhabit, and place-identity, i.e. symbolic attributes of locations that individuals incorporate into their personal and social identities (Uzzell, Pol, and Badenas, 2002; Devine-Wright and Howes, 2010). Natural places such as forests and parks have been shown to be highly valued and to lead to the strongest place attachment (see Lewicka, in press, for a review), while place-attachment and place-identity have been linked to the construction of place-related risks. For example, residents tend to discount the risks present in their immediate or local environment, sometimes showing more concern for global than for local environmental problems, or more concern the farther they live from them (Uzzell, 2000; Räthzel and Uzzell, 2009). Residents living close to incinerators 
(Lima, 2004), polluted beaches (Bonaiuto, Breakwell, and Cano, 1996), or nuclear plants (Parkhill, Pidgeon, et al., 2010) have been shown to distance themselves from local risks or to normalize them and integrate them in their daily lives, arguably in order to cope with them on a daily basis. Scenic beauty and the restorative functions of rural places have been shown to lead to people's higher resistance to the disruption brought about by environmental intrusions, such as wind turbines (Devine-Wright and Howes, 2010), thus suggesting that idyllic rural places may not lend themselves easily to anchoring representations of risk.

\section{Objectives of the paper}

The focus of this paper is to explore how people make sense of risk and the recommended ways of responding to it when they are largely unfamiliar with the nature of the risk although there is a familiarity with the places in which it occurs. The aim of the current study is twofold: to outline the knowledge claims that countryside users make concerning LD, and to detail the discursive strategies that people use in order to construct their position in relation to the risk and how they should respond to it. In addressing these aims we are particularly interested in how the countryside - the place where the risk is situated - is used to legitimate the positions that are taken.

\section{Method}

\section{Design}

A semi-structured interview schedule was designed comprising questions about: (i) the visitors' views on the positive and negative aspects of the countryside and on what 
constitutes risk in the countryside; (ii) their views on risk information provision in the countryside; (iii) the visitors' knowledge of and perceptions of risk from LD; (iv) their motivations for precautionary measures against tick bites and LD; and (v) their preferences for information provision in relation to LD.

\section{Participants}

Sixty-six interviews, some involving couples or pairs of friends, were conducted with 82 randomly selected participants, 48 females and 34 males, age range $=18$ to 68 , Mean age $=38.34$, at three recreation sites. The interviews were conducted by the first author in May to September $2009.93 .90 \%$ of the participants $(n=77)$ were of 'white-UK' ethnic origin. $79.3 \%$ of the participants $(n=65)$ visited the countryside frequently (ranging from daily to once or twice a month). $59.80 \%$ of the participants $(n=49)$ visited the site where the interview took place from once or twice every few months to once or twice a week. Some participants, $15.9 \%(n=13)$, were at the interview site for the first time: $33.3 \%(n$ $=8)$ in Exmoor, 9.1\% $(n=3)$ in the New Forest, and 8\% $(n=2)$ in Richmond Park. The participants' presence at the sites was taken to indicate either lack of awareness of the hazard of tick bites and LD, or awareness and acceptance of the hazard.

\section{The interview sites}

The interviews were conducted in Richmond Park (a peri-urban park), New Forest (an example of 'accessible countryside'), and Exmoor (an example of 'remote upland'). All three sites are tick habitats and all have been linked to incidence of LD. Richmond Park, London's largest park, sustains large deer herds and is located in a largely affluent, 
middle-class neighbourhood, and it is used by residents and visitors for walks, family picnics, sunbathing, dog walking, playing golf, cycling, etc. In Richmond Park, the interviews were conducted with people sitting or picnicking on the grass on Spanker's Hill and Roehampton Gate areas.

The New Forest is an area in the southern county of Hampshire comprising towns, villages, pasture land, forest, and heathland. The New Forest National Park has a rich wildlife, including deer and adders, and is a destination for day trips, picnics and barbeques, hiking, and camping. In the New Forest, the interviews were conducted with people sitting on the grass or barbequing at a picnic site, Bolderwood, which also serves as a starting point for forest hiking trails.

Exmoor National Park is a national park comprising small towns and villages in the south-west of England, in a remote coastal area characterized by heather moorland, forest, valleys, and rugged coastline. In Exmoor the interviews were conducted the Watersmeet café, a former fishing lodge now tea room and shop managed by the National Trust, located in a wooded area.

\section{Procedure}

The first author approached visitors at the three sites and invited them to take part in a recorded interview about their views of the countryside. Informed consent was obtained in writing prior to the start of the recording, and the participants were compensated with $£ 5$ in vouchers for their time (one voucher per interview). At the end of the interview they were debriefed and were handed information about LD taken from the NHS Direct website. The participants were also handed a copy of the LD leaflet issued by the 
respective interview site (e.g. Richmond Park). In those cases where the participants had no knowledge of LD, the interviewer explained what LD was, how it is transmitted by ticks, and what the precautionary measures are. The information provided was based on the NHS Direct website.

\section{Analytic strategy}

The analysis of the interviews was informed by thematic analysis (Braun and Clarke, 2006). Some themes were based on explicit meanings or the manifest content of the data, which was directly observable, while other themes were based on latent content and drew on wider influences such as cultural values attached to restoration in the countryside. The analysis was recursive as it involved a constant moving back and forth between the data itself and the themes that were constructed. Our analysis shared assumptions with a SRT approach to risk (Joffe, 1999; 2003), as we were interested in how participants constructed meanings concerning the risk of LD in the context of the countryside. Under each quote, used to illustrate the main points being made, we indicate the location and number of interviews with initials, e.g. RP1 for Richmond Park interview 1, NF2 for New Forest interview 2, E3 for Exmoor interview 3, and the participants' gender, age, and town or county of residence. The participants' responses are indicated in italics.

\section{Findings and Discussion}

First we present evidence of the nature of the knowledge claims that participants made about LD. Following this we have identified three themes in the data that depict the way in which understandings of risk are anchored in claims about the countryside: the 
countryside as a restorative place, the everyday experiences of the countryside, and constructing a countryside identity. Finally, we will consider how preferences for precautionary action are anchored in the representations of LD and of countryside practices.

\section{Constructing knowledge about LD}

First, we examined how visitors construct their knowledge of LD. The majority of the participants had heard of LD, but in many cases knew very little about its causes, symptoms, or prevention and were ostensibly unconcerned by this.

Have you ever heard of diseases such as Weil's disease or Lyme disease?

Lyme, I have, but I don't know anything about it. I've heard of it.

Do you know how serious... do you have any idea how serious Lyme disease is?

No. (E3: F, 33, Gloucestershire)

Lyme disease, I've heard of it but I don't know exactly how it's transmitted. [...] I have heard of it, but I haven't particularly absorbed it to say that it's caused me any concern.

(NF5: F, 58, Poole)

Em, isn't that where it's just like the ticks that get into the skin? I can imagine it's fairly serious, but not like majorly. (NF4: F, 31, Hampshire)

Oh yes, I have heard of it! I've heard of it, yeah, because, last year, they were quite concerned, weren't they? They were saying, if you walk - there were more ticks than usual, 
and to be careful if you were walking in long grass, to check that you don't get ticks.

(RP13: F, 43, London)

Even participants that were regular countryside users or those that had been diagnosed with LD readily admitted that their knowledge was patchy. Certainly there was no evidence from any participants that lack of knowledge was linked to concern.

[Ticks] are rather vile little creatures, aren't they? But no actually, on a scale of concern, probably it wouldn't even register one. It's not...it's unlikely that it's going to give me that disease... what is it...is it Lyme's disease... and they can be pulled off. So, no, I'm not really bothered, and if it did become infected, I would just trek off to the doctors and get antibiotics. (NF12: F, 47, Dorset)

Yeah, oh yeah, I had a tick bite once from... Yeah, and that went a bit funny, and I had to have antibiotics...on my ankle, yeah.

Oh right, so you know about ticks and Lyme disease...

Yeah.

So you know how you get Lyme disease?

Well, only through...only because of ticks, yeah. I don't actually know what Lyme disease is. (E7: F, 32, Devon)

In summary, LD was largely unfamiliar to people (cf. Sheaves and Brown, 1995), and thus this domain is ideally suited to exploring the fine grained processes of meaning making and representation and, more specifically, the role of representations of the 
countryside in this regard. Building on this, three main themes illustrate the way in which the risk of LD is anchored to the countryside.

\section{The countryside as a restorative place}

Interpretations of risk were linked to a strong representation of the countryside as a rural idyll and a source of restoration. These representations were juxtaposed against the countryside being linked to LD - the incongruity of this was used as a way of characterizing the risk of LD as unlikely to occur and unlikely to impact on the visitors' regular use of the countryside. The countryside was constructed as a restorative environment where people could relax, recharge their batteries and be away from the 'hustle and bustle' of urban areas, and indeed away from risks:

F: It's a safer environment than the one that we live in to cycle. It's infinitely more interesting for dog walking, and it's out of the way.

M: And you experience a healthy, outdoor approach. It makes you feel better. It recharges your battery before you go back to work, especially on a Bank Holiday. (NF12: F, 47, Dorset, and partner, M, 50, Hampshire)

We just like the fresh air and going out walking [...] looking at all the different plants and flowers and, yes, flora and fauna, you know. [...] If you worried about all these things, you'd never leave your house! I mean, there'd be too much to worry about. We come out for a walk in the countryside to forget about worrying about things really. (E22: F, 46, Birmingham) 
Certainly, participants did not readily associate the countryside with dangers, and though admitting that risks must be present as in any other place the notion of the countryside harbouring risk was clearly peripheral to their representation.

Do you ever think of the countryside as having potential dangers, potential risks? I guess it's not something I'd probably go out on my own. I guess there are sort of safety risks, depending on how remote a place you're in...hazards...I guess fallen trees, etc., but other than that, no. I don't really... maybe I...it's not something I think of when I do go. Maybe it's something I'll probably face when I'm there rather than ... (RP3: F, 29, London)

Potential hazards...em, not really, no. If people...well, what could be a hazard? I don't really know... [...] Okay, you may walk under a tree and a branch may fall on your head, but you may be in the city and you get struck by lightning. It's all chance, isn't it? If you're just generally aware of your surroundings... (NF21: M, 39, Hertfordshire)

Participants were thus able to preserve their view of the countryside as a benign and restorative place and, acknowledging the ubiquity of risk, justified a relaxed attitude regarding countryside risks.

[I like] walking and getting exercise and fresh air, all that sort of stuff, being out in the open, is a very, very important thing. It just is... just very good for body and soul really basically. [...] I think the risks are very, very low. I suppose...there is the very, very low risk that you could be on your own in the countryside and you might suffer ill health, of course. That could happen. Alternatively, I suppose, you could... be very, very unlucky, and come across somebody who is threatening. But I...those risks are probably there in life 
generally, and I don't see any particular and specific risks about being in the countryside, personally. (E18: M, 58, Hampshire)

The core of social representations of the countryside did not readily admit the incorporation of notions of risk. At best, risk was a peripheral element of the social representation of the countryside, and as such did not provide a basis for the anchoring of the risk of LD.

In line with the notion that the countryside is predominantly benign and a source of restoration, participants argued that there warning signs about countryside risks would spoil the environment and be an 'eyesore'. The intrusion of risk, in the form of warnings was considered inappropriate in this environment:

What I wouldn't want is to come here and find, on every road junction, great big information hoardings with warning this, warning that, warning the other, so it's...there's a balance point at which... Because that then detracts from the pleasantness. [...] I want to come here and look at trees, and not look at great big flashing beacons and neon signs, you know. (NF1: M, 48, Hampshire)

I think it's getting the balance right, because it's...the countryside is the countryside, and it's green and it's wild and it's plants and animals, and if you start polluting it by putting up loads of warning signs... A slippery path is a slippery path, and you should be able to see it without having to have a slippery path sign. I think it would pollute...pollute the visual aspect if there were lots of signs warning you every five minutes of the obvious. (E6: M, 60, Gloucestershire) 
I think you ruin the natural beauty of it by putting up signs. (NF3: M, 44, Dorset)

As the quotes above illustrate, the participants used the restorative quality of the countryside as a baseline for adjudging the risk and the way in which information about the risk was provided.

\section{Everyday experiences of the countryside}

A lack of concern and even dismissal of the risk was warranted in relation to previous experience in the countryside, and permitted the claim that the participants themselves were not likely LD ‘candidates’ (cf. Frich, Malterud, and Fugelli, 2007). The claim that the risk was minimal was constructed by juxtaposing the frequent experience of spending time in the countryside with never having contracted LD. In the quote below the possible consequences of LD are seen as being serious but this is discounted through an assessment of low probability.

I don't feel that ticks or adders are a particular danger to me personally. [...] I think that, you know, how many times are you going to walk through bracken and actually pick up ticks? It's not going to be every time, and it's not going to be the majority. (E5: F, 37, Devon)

Similarly, not knowing anyone who had bitten by ticks was used as a justification for why the risk of LD did not apply to oneself. Extreme case formulations such as 'never', 
'anybody', 'ever', 'lots of people' served to justify people's sense of invulnerability to the risk:

I don't think there really is a problem with it, unless... you know, there's something we don't know and lots of people are getting bitten by ticks, but I'm certainly not aware of anybody in the New Forest that's ever been bitten by a tick. I don't think they choose to stay on humans, really. (NF3: F, 44, Bournemouth)

I've never been concerned about them because I've never actually...em ...known anybody that's been bitten by one, personally. You know, so I've never probably been in the sort of environment where they exist, although I'm sure they do in fields where cattle are and sheep and horses and so on. They probably are there, but I've never...em...never had one bite me [laughing]! (E23: F, 59, Hertfordshire)

You don't hear about these things, do you, so it can't be a great risk to people, otherwise, you know, you wouldn't get people coming to these parks and running around and enjoying themselves. (RP1: F, 31, Guildford)

Other participants considered tick bites as a normal occurrence in the countryside, and engaged in narratives of acceptance of the ubiquity of risks such as ticks (cf. Weaver, Murtagh, and Thomson, 2006):

No, I don't really know anything about it [LD]. I mean, we've all had ticks, and we just get them out and that's it. (NF6: F, 25, Hampshire) 
Making sense of Lyme disease

Well, because they can't really kill them all, can they? There's nothing you can do about the ticks really. They're there and that's it. (NF6: F, 25, Southampton)

\section{Constructing a countryside identity}

In some cases, the participants created an identity that helped them distance themselves from the risk of LD, such as 'having grown up in the countryside' or 'being a country person', where the nature of this identification with the countryside somehow conferred immunity on them:

Oh god, no, no! It wouldn't worry me at all, but then, you know, we've kind of...we've grown up in the country, so we're not really too worried about it. (RP8: female, 39, London)

Well, I grew up in the countryside, and I remember my dog having ticks, and us burning them off. I don't think it's serious. You know, it wouldn't worry me. (RP13: F, 43, London)

In another example when the interviewer explained what the range of precautions might include, the nature of the link between the person and the countryside was used to discount the risk:

I haven't the faintest idea. I don't know whether there is - maybe there is some protection. I really don't know. I don't think about it.

The simplest thing to do is just to wear, you know, kind of like long sleeves and long trousers. 
Oh, I don't worry about that.

And not to brush up against vegetation, you know, where you might pick them up.

Yeah. You know, I'm a country person really, so I just don't...don't think about it, no.

(RP5: F, 68, London)

In the following quote it is the juxtaposition of never having heard of a disease that is located in a place you have grown up in that allows the risk to be constructed as a minor one, and one where care is needed lest communication becomes scare-mongering:

I think the risk has got to be...has got to be weighed up against the possible damage it could do by sort of scaremongering, you know, frightening people, telling them all about Lyme disease and blah-blah-blah-blah. I've never heard of Lyme disease, and I grew up here [Exmoor].[...] I wouldn't make a big issue out of it, because I think it would put people off, especially people with kids, you know. It would probably put them off, and you've got to outweigh the...you've got to weigh the risks up, haven't you? Obviously, it can't present a massive problem, Lyme disease - I don't think anyway, personally. (E4: M, 42, London)

As can be seen from the extracts above, constructing an identity for oneself as a 'country person' justifies people's lack of worry and precautionary action against LD, showing how place-identity can be used as a resource for discursive action (Dixon and Durrheim, 2000).

\section{Precautions against LD in the countryside}


The way in which preferences for precautionary action against LD are anchored in the representations of ticks and of the countryside ultimately have policy and practical implications. Some precautionary measures against LD were linked to precautions that the participants took against insect bites, e.g. insect repellent, and such anchoring rendered the precautions against tick bites as acceptable and 'commonsense'. However, other precautionary measures, e.g. wearing long sleeves, were constructed as intrusive and at odds with the experience of some countryside activities (e.g. enjoying the sunshine). Claims made about the importance of immersion in common country practices provided the discursive resources to dismiss the necessity of taking precautions. In the visitor response below, alongside a narrative of inevitability this participant also prioritised the need for clothing to be attuned to the weather, rather than covering up to avoid ticks:

Em, I tend to wear what's right for the weather rather than, you know, are the ticks going to be out today. [...] Apart from warning people about tick bites, they can't eradicate them, so... if they're there, they're there, aren't they? (E6: M, 60, Gloucestershire)

I'd want to be very clear that there was a very significant risk before I wore long trousers on a lovely hot day, for example, or... So it would have to be quite a significant risk-i.e. a reasonable proportion of people had problems from tick bites, rather than just one person a year, for example. I don't know what the prevalence is. (E15: F, 39, Bristol)

Taking some of the recommended precautionary measures against LD were constructed as inconvenient and difficult to put into practice (cf. Woodcock, Stenner, and Ingham, 
1992) because they clashed with people's physical comfort or enjoyment of the countryside:

Yeah, we do stay on the paths really, but...I wouldn't necessarily wear long... You know, like today, it's a hot day. (NF6: F, 25, Southampton)

Do you know how to protect yourself against tick bites?

F: Eh, no...I guess some sort of insect repellent, I presume.

Yeah, insect repellent and also, you know, to wear long trousers, long sleeves, you know, when you go out into the forest.

M: But see, that's something that I wouldn't want to do. I wouldn't want to come out other than like this (pointing to T-shirt). (NF22: M, 46 and F, 43, Berkshire)

Even the provision of precautionary advice was constructed as clashing with the inherent restorative values of 'unspoilt' nature. The rejection of precautionary information as unnecessary governance (cf. Barnett et al., 2008) was facilitated by the social representation of the countryside as a place of restoration and of tranquil beauty:

Yeah, but do you really want leaflets handed out in a park that just sort of will, you know, mean people are more likely to litter? And then boards basically get rid of nature itself because you've got signs everywhere about some completely irrelevant disease. (RP10: M, 25, London) 
Yeah, I suppose so, but if they put small notices up, people probably aren't going to read them anyway, and you can't really put huge notices up saying "Beware of ticks", can you?

(NF3: F, 44, Dorset)

Overall, this theme illustrates that the established practices of restoration in the countryside often precluded the acceptance of precautionary information and measures against LD, and that people may prefer precautions which do not interfere with their everyday use of the countryside.

\section{Conclusions}

The focus of this research has been on lay risk reasoning in relation to unfamiliar risks encountered in the countryside, a place which is typically perceived and valued as restorative and risk-free. It has focussed on the social representations through which unfamiliar risk is filtered. We have examined key place-related filters provided by the familiar context of the countryside with regard to the unfamiliar risk of LD, and we have located lay reasoning about LD in relation to wider social practices related to countryside use. A number of significant findings have arisen from the analysis of visitors' discourses about countryside risks and LD.

First, the visitors' discourses about the familiar practices associated with the countryside and the unlikely risk of LD reflect the health conundrum hypothesised at the beginning of this paper in which the restorative qualities of countryside use sits in opposition to the need to provide information on rare and potentially off-putting countryside risks (Quine et al., in press). The participants provided a social representation of the countryside where 
risk was only a peripheral element. They often argued that risk information provision under the form of signs and leaflets would spoil the countryside as a natural place and would impinge on people's restorative practices. The respondents' downplaying of the risk of LD suggests that the provision of risk information about zoonoses such as LD does not necessarily produce a reaction of flight from the countryside as some risk frameworks might suggest (see Quine et al., in press). Instead, the positive social representations of the countryside and the deep-seated practices of countryside use act as a filter which percolates the risk information and precludes responses of panic or outrage. These results suggest that policy makers and countryside authorities should not shy away from providing information on possible health risks as it is unlikely that this would act as a barrier against countryside use.

Second, regarding the role of the countryside as a filter for risk understanding, the results indicate that restorative aspects formed the core representation of the countryside and were clearly discrepant with the notion of risk. This equipped participants to be able to distance themselves from concern about the risk and from the necessity to take action. The participants' risk reasoning was mainly pragmatic and filtered by their use of the countryside as a place of escape and restoration. Place-attachment seemed to preclude an understanding of $L D$ as a threat to health; the significance of place attachment was such that LD represented a threat to the values and social practices attached to the countryside. The precautionary measures, too, were translated as a threat and were often constructed as running counter to the activities that people normally undertook in this context, while the provision of precautionary advice was often constructed as intrusive governance. 
Third, in relation to LD, the visitors did not respond with panic and outrage, but rather with distancing and protective strategies such as claiming a countryside identity. While in some cases the participants believed that LD could be serious, they nonetheless perceived it as a very rare occurrence within their normal practices. Furthermore, many participants rejected the suggested precautionary measures such as staying on paths or wearing long trousers and sleeves, asserting that they were at odds with their usual patterns of countryside use. Arguably, these strategies function as symbolic coping (Joffe, 2003) as the respondents were more concerned about protecting their personal freedoms and the values they attached to restoration in the countryside than their own health. This supports the SRT view that identity processes influence the choice of social representations of risk (Joffe, 1999; Breakwell, 2001a).

As for the practical implications of this work for policy and practice, the present findings seem to suggest that the precautionary measures against LD would benefit from being framed as being part and parcel of the social practices of countryside recreation so as to minimize the scope for reactance. Equally, countryside visitors could be advised to take precautions that have minimum impact on their practices, e.g. checking for tick bites when returning home instead of taking precautions prior to their visit by dressing in unpreferred ways or covering skin during their visit. However, this is not to say that organized responses to the hazard of LD should necessarily be driven by public perceptions of the hazard; instead, we are suggesting that such organized responses could benefit from insights into how the public understand countryside hazards, how they 
respond to their communication, and how they alter their behaviour in response.

Furthermore, such an approach may be limited to LD: other zoonoses may require different management strategies as a function of their degree of severity, their public perception, or the existing social practices that expose the public to the risk.

Overall, this research has shown that the social representation of the risk of LD is filtered by the emotive and social components of attachment to the countryside, and in some cases people's identity as a country person. Instead of constructing LD as a risk to health, the participants in our study constructed LD mainly as a risk to their restorative practices in the countryside. The potential contrast between precautionary messages and apparently risk-free contexts raises issues as to how people respond to risk communication and engage in precautionary measures. It also raises questions as to whether the way in which countryside authorities currently provide risk information and encourage precautionary behaviour is the most effective.

\section{References}

Abric, J.-C. (Ed) 1994. Pratiques Sociales et Représentations. Presses Universitaires de France, Paris.

Aronowitz, R. A., 1991. Lyme Disease: The Social Construction of a New Disease and Its Social Consequences. The Millbank Quarterly, 69, 79-112.

Augoustinos, M., Walker, I., 1995. Social Cognition: An Integrated Introduction. Sage, London. 
Barnett, J., Timotijevic, L., Vassallo, M., Shepherd, R., 2008. Precautionary advice about mobile phones: public understandings and intended responses. Journal of Risk Research, 11, 525-540.

Bonaiuto, M., Breakwell, G.M., Cano, I., 1996. Identity Processes and Environmental Threat: the Effects of Nationalism and Local Identity upon Perception of Beach Pollution. Journal of Community and Applied Social Psychology, 6, 157-175.

Braun, V., Clarke, V., 2006. Using thematic analysis in psychology. Qualitative Research in Psychology, 3, 77-101.

Breakwell, G. M., 2001a. Mental models and social representations of hazards: the significance of identity processes. Journal of Risk Research, 4, 341-351.

Breakwell, G. M., 2001b. Social Representational Constraints upon Identity Processes. In Deaux, K., Philogène, G. (Eds) Representations of the Social: Bridging Theoretical Traditions. Blackwell, Oxford.

Conradson, D., 2005. Landscape, care and the relational self: Therapeutic encounters in rural England. Health \& Place, 11, 337-348.

Devine-Wright, P., 2009. Rethinking NIMBYism: The Role of Place Attachment and Place Identity in Explaining Place-protective Action. Journal of Community \& Applied Social Psychology, 19, 426-441.

Devine-Wright, P., Howes, Y., 2010. Disruption to place attachment and the protection of restorative environments: A wind energy case study. Journal of Environmental Psychology, 30, 271-280.

Dixon, J., Durrheim, K., 2000. Displacing place-identity: A discursive approach to locating self and other. British Journal of Social Psychology, 39, 27-44. 
Frich, J. C., Malterud, K., Fugelli, P., 2007. How do patients at risk portray candidates for coronary heart disease? A qualitative interview study. Scandinavian Journal of Primary Health Care, 25, 112-116.

Halfacree, K. H., 1995. Talking About Rurality: Social Representations of the Rural as Expressed by Residents of Six English Parishes. Journal of Rural Studies, 11, 120.

Hallman, W., Weinstein, N., Kadakia, S., Chess, C., 1995. Precautions Taken Against Lyme Disease at Three Recreational Parks in Endemic Areas of New Jersey. Environment and Behavior, 27, 437-453.

Hartig, T., 2008. Green space, psychological restoration, and health inequality. Lancet, $372,1614-1615$.

Herrington, J. E., 2004. Risk perceptions regarding ticks and Lyme disease: a national survey. American Journal of Preventive Medicine, 26, 135-140.

Horlick-Jones, T., Walls, J., Kitzinger, J., 2007. Bricolage in action: learning about, making sense of, and discussing, issues about genetically modified crops and food. Health, Risk and Society, 9, 83-103.

Joffe, H., 1999. Risk and 'the Other'. Cambridge University Press, Cambridge.

Joffe, H., 2003. Risk: From perception to social representation. British Journal of Social Psychology, 42, 55-73.

Jovchelovitch, S., 2002. Re-thinking the diversity of knowledge: Cognitive polyphasia, belief and representation. Psychologie et Societé, 5, 121-138. 
Jovchelovitch, S., 2008. The Rehabilitation of Common Sense: Social Representations, Science and Cognitive Polyphasia. Journal for the Theory of Social Behaviour, $38,431-448$.

Karjalainen, E., Sarjala, T., Raitio, H., 2010. Promoting human health through forests: overview and major challenges. Environmental Health and Preventive Medicine, $15,1-8$.

Lewicka, M. (in press) Place attachment: How far have we come in the last 40 yeas? Journal of Environmental Psychology, doi: 10.1016/j.jenvp.2010.10.001.

Lima, M. L., 2004. On the influence of risk perception on mental health: Living near an incinerator. Journal of Environmental Psychology, 24, 71-84.

Macaskill, M., 2009. Prince of Wales backs deer 'tick mop' plan. The Sunday Times.

Mawby, T. V., Lovett, A.A., 1998. The public health risks of Lyme disease in Breckland, UK: An investigation of environmental and social factors. Social Science and Medicine, 46, 719-727.

Moscovici, S., 1984. The phenomenon of social representations. In Farr, R. M., Moscovici, S. (Eds) Social representations Cambridge University Press, Cambridge.

Moscovici, S., 1988. Notes towards a description of social representations. European Journal of Social Psychology, 18, 211-250.

Moscovici, S., 2000. Social representations: Explorations in social psychology. Polity Press, London.

Opotow, S., Weiss, L., 2000. Denial and the Process of Moral Exclusion in Environmental Conflict. Journal of Social Issues, 56, 475-490. 
Parkhill, K. A., Pidgeon, N.F., Henwood, K.L., Simmons, P., Venables, D., 2010. From the familiar to the extraordinary: local residents' perceptions of risk when living with nuclear power in the UK. Transactions of the Institute of British Geographers, 35, 39-58.

Quine, C. P., Barnett, J., Dobson, A.D.M., Marcu, A., Marzano, M., Moseley, D., O'Brien, L., Randolph, S.E., Taylor, J.L., Uzzell, D. (in press) Frameworks for risk communication and disease management: the case of Lyme disease and countryside users. Philosophical Transactions of the Royal Society B.

Räthzel, N., Uzzell, D., 2009. Changing Relations in Global Environmental Change. Global Environmental Change, 19, 326-335.

Ronn, S. J. D., 2009. In the Lymelight: Law and Clinical Practice Guidelines. Southern Medical Journal, 102, 626-630.

Shadick, N. A., Daltroy, L.H.,Phillips, C.B., Liang, U.S., Liang, M.H., 1997. Determinants of tick-avoidance behaviors in an endemic area for Lyme disease. American Journal of Preventive Medicine 13, 265-270.

Sheaves, B. J., Brown, R.W., 1995. A Zoonosis as a Health Hazard in UK Moorland Recreational Areas: A Case Study of Lyme Disease. Journal of Environmental Planning and Management 38, 201-214.

Smith, A. W., Baum, A., 2003. The Influence of Psychological Factors on Restorative Function in Health and Illness. In Suls, J., Wallston, K.A. (Eds) Social Psychological Foundations of Health and Illness. Blackwell Malden, MA.

Stern, P. C., Dietz, T., 1994. The value basis of environmental concern. Journal of Social Issues, 50, 65-84. 
Tonks, A., 2007. Lyme wars. British Medical Journal, 335, 910-912.

Uzzell, D., Pol, E., Badenas, D., 2002. Place identification, social cohesion and environmental sustainability. Environment and Behavior, 34, 26-53.

Uzzell, D. L., 2000. The psycho-spatial dimension of global environmental problems. Journal of Environmental Psychology, 20, 307-318.

Weaver, N. F., Murtagh, M.J., Thomson, R.G., 2006. How do newly diagnosed hypertensives understand 'risk'? Narratives used in coping with risk. Family Practice, 23, 637-643.

Woodcock, A. J., Stenner, K., Ingham, R., 1992. Young people talking about HIV and AIDS: Interpretations of personal risk of infection. Health Education Research: Theory and Practice, 7, 229-247. 